\title{
Re-view
}

\section{Cutting Rhythms: A New Perspective on the Rhythmic and Choreographic Nuances of the Edit}

\author{
Cari Ann Shim Sham*
}

Cutting Rhythms: Shaping the Film Edit. By Karen Pearlman.

Burlington, MA: Focal Press, 2009. Pp. 269. \$39.95 (paper).

$\mathrm{R}$

olled corners, post-it note covered, writing in the margins and dog-eared pages are the signs of a well-used book. When I look at my copy of Karen Pearlman's 2009 publication Cutting Rhythms I realize that I might need to get another copy. After just one pass at this book, it looks as if I've spent a lifetime with it. I must admit that while reading it, I had a very hard time putting the book down and couldn't quell my excitement whenever I came upon a cohort in the world of editing, filmmaking or dance for camera, blurting out "you've gotta read this book!" Cutting Rhythms seeks to deepen the understanding and definitions of rhythm in the shaping of the edit. It also investigates how the body of the editor experiences the physical act of cutting. The book's author is interested in undoing the mysticism of the craft by explaining in layman's terms over-used or undefined words in the field such as "intuition." In her Preface, Pearlman states, "the idea was to base my research on words that are frequently used, but infrequently defined in the regular course of editing a film, such as 'structure,"montage,'and 'rhythm"' (ix). And she does just that.

In twelve chapters Pearlman gracefully covers a wide range of issues and technical definitions for more deeply understanding the practice of editing. Chapter 1, as its title implies, addresses "Rhythmic Intuition" by discussing intuitive thinking. She bravely explores, breaks apart and examines the topic of intuition. She begins by quoting Donald Schon, who writes: "When people use terms such as 'art' and 'intuition,' they usually intend to terminate discussion rather than to open up inquiry" (2). Pearlman argues that "intuition" is commonly used as an excuse, as a means to avoid technical or scientific explanation of an editor's craft, thus allowing editorial practice to remain mysterious. She challenges this by defining intuition on several levels, and ventures into the unclaimed territory of topics ranging from explicit knowledge, implicit learning, and kinesthetic empathy to, finally, my personal favorite, mirror neurons (a new and exciting subject that is springing up in science and dance scholarship). She finishes the chapter by explaining how rhythm is perceived, learned, practiced, and applied in editing. 
In Chapter 2, "Editing as Choreography," Pearlman draws on her movement experience to explain the art of the edit as "a dance," a move that illuminates Pearlman's ability to weave her perspective and experience as a dancer into understanding rhythm in editing. Chapter 3, "Timing, Pacing and Trajectory Phrasing," and Chapter 4, "Tension, Release, and Synchronization" are clear and straightforward in their content, and support her introduction of a new concept: "Trajectory phrasing,"' Pearlman writes, "is a term I have devised to cover an area of editing rhythms that is not precisely addressed by the terms 'timing' and 'pacing'" (52). Pearlman, however, can also come across as heavy-handed at times. For example, in Chapter 4 she presumes to speak out for all editors in a personal tirade: "Editors hate it when directors snap their fingers or hit the table to indicate where they want a cut because these gestures, as well as expressing a kind of dictatorship or distrust of the editor's intuition, can actually jump between the editor and her own feeling for the material" (70).

Chapters 5 through 8 explore different types of rhythm found in traditional film editing, including physical, emotional and event rhythms. In these chapters the author analyzes popular film scenes as visual tools to explain various editing conventions and stylistic choices, staying within the familiar territory of classics such as The Godfather and Gone with the Wind, to name two.

Chapter 9, "Style," discusses collision, linkage, montage, and decoupage. Her definitions of the latter two alter the French use of the words, "drawing on the common understanding of the term among English-speaking editors," and might be considered biased among nonWestern audiences. Chapter 11, "Common Scenes," is a breakdown of two-handers and chases; I found it to be the least interesting section in the book.

Pearlman's twelfth chapter is the conclusion of the book and my favorite piece of writing. Through definitions, explanation and reassignments of meaning, Pearlman constructs an apparatus of rhythm theory that suggests similarities between choreography and editing - why, that is, the two make good bed partners. This speaks deeply to me and helps me to better comprehend how l've found myself understanding the edit through my own dancing body's experience. Pearlman writes: "Choreographers make dance phrases, and editors make cine-phrases, but both are shaped by the tools of timing, pacing and trajectory phrasing ... consideration of the choreographic possibilities for shaping movement and energy over time is one way of understanding and possibly expanding the craft of cutting rhythms" (248).

Being a filmmaker and editor who teaches in the field of dance, I find Cutting Rhythm to be a great addition to the classroom or reading list for anyone teaching or studying the form. Pearlman includes helpful exercises and role-playing assignments throughout the book that would be useful in workshop or classroom situations. Considering there are few books written on the topic of the edit in relation to rhythm and movement, Pearlman is a big fish in a small pond. This text forges new territory of multi-disciplinary analysis that serves as an enlightening resource for editors, filmmakers, and choreographers working in dance and or film. Pearlman's rigor and the specificity with which she explores her topic, the shaping of the edit, is unmatched. She so thoroughly explores, explains, and demonstrates varying ideas on rhythm and the shaping of the edit that any editor, amateur to professional, will come away with new and useful information.

If I were to offer any critique, I dare say, I was very distracted by her choice of only using the gender specific pronouns "she" or "her" throughout the entire book. It seems to me an 
unnecessary and distracting gender politicking in an otherwise brilliant piece of writing. Congratulations to Pearlman for tackling such a mysterious subject and contributing a strong new addition of material to our libraries, studios, classrooms, and bedrooms, as well as to all who collectively share the love of dance and camera, movement and screens, rhythm and the edit. 